\title{
The effect of two nucleoside antitumor drugs on the proliferation and DNA methylation of human gastric cancer cells
}

\author{
XIU-LI CHEN $^{1,2^{*}}$, FENG-MEI WANG $^{3 *}$, JIA-JIA LI $^{1 *}$, XIAO-YING HE $^{1}$, XI-YU LIU $^{1}$ and LI-BING MA ${ }^{1}$ \\ ${ }^{1}$ School of Mathematics, Physics and Biological Engineering, Inner Mongolia University of Science and Technology, \\ Baotou, Inner Mongolia 014010; ${ }^{2}$ Faculty of Biological Science and Technology, Baotou Teachers College; \\ ${ }^{3}$ School of Farm and Garden Engineering, Baotou Light Industry Vocational Technical College, \\ Baotou, Inner Mongolia 014030, P.R. China
}

Received September 6, 2014; Accepted June 2, 2015

DOI: $10.3892 / 01.2015 .3427$

\begin{abstract}
Fluorouracil (5-Fu) and 5-azacitidine (5-aza) are two types of nucleoside analog, which have been widely applied in the treatment of several types of cancer. However, the effect of these two types of drug on the proliferation and DNA methylation of cancer cells has not been compared in a single study. In the present study, in vitro cultured human gastric cancer cells (hGCCs) were treated with various concentrations of 5-Fu and 5-aza, and cell counting, MTT assay and methyl-sensitive amplified polymorphism were used to evaluate the resulting levels of proliferation and DNA methylation of hGCCs. The results revealed that the two drugs were able to inhibit the proliferation of hGCCs, but that the effect of 5-aza was weaker than that of 5-Fu. However, 5-aza decreased the level of DNA methylation in hGCCs, whereas 5-Fu did not alter DNA methylation. These results indicated that $5-\mathrm{Fu}$ was able to more efficiently inhibit the proliferation of hGCCs than 5-aza, and that this difference may be due to differences in the anticancer mechanism of these two types of drug.
\end{abstract}

\section{Introduction}

Cancer, also known as malignant tumor, represents a significant threat to human health. Tumorigenesis occurs as a result of the activation of oncogenic pathways and/or inactivation of tumor suppressor pathways (1). Changes in the DNA sequence, including mutations, amplifications, gene rearrangements or deletions, were hypothesized to underlie

Correspondence to: Professor Li-Bing Ma, School of Mathematics, Physics and Biological Engineering, Inner Mongolia University of Science and Technology, Tengfei Building D Block, 7 Arding Street, Baotou, Inner Mongolia 014010, P.R. China

E-mail:mlb-xn2004@163.com

${ }^{*}$ Contributed equally

Key words: human gastric cancer cell, 5-fluorouracil, 5-azacitidine, cell proliferation, DNA methylation tumorigenesis (2); however, aberrant epigenetic modifications also have a important role in cancer occurrence and progression. For example, DNA methylation, a type of epigenetic modification, was found to exhibit a distorted pattern in human cancer cells (3). Hypomethylation of intergenic regions and hypermethylation within the promoter regions of numerous $\mathrm{CpG}$ island-associated tumor suppressor genes has been observed in cancer cells $(4,5)$. Hypomethylation of intergenic regions may result in the activation of transposable elements and instability of the genome in cancer cells (6), while hypermethylation of promoter regions may result in the silencing of tumor suppressor genes and uncontrolled cancer cell proliferation (7). Therefore, various types of DNA methyltransferase inhibitors have been used in cancer therapies (8). Fluorouracil (5-Fu) and 5-azacitidine (5-aza), two types of nucleoside analog, have been used to treat several types of cancer $(8,9)$. However, the anticancer mechanisms underlying the effects of these two types of drug are distinct. Firstly, 5-aza is a type of DNA methyltransferase inhibitor, which is incorporated into DNA, leading to inhibition of DNA methylation and restoration of the expression of silenced tumor suppressor genes $(10,11)$. By contrast, 5-Fu is a type of antimetabolite drug, which inhibits essential biosynthetic processes via incorporation into DNA and RNA, consequently inhibiting the normal function of these macromolecules in cancer cells (9). Although these two types of drug have been widely applied to treat various types of cancer, their effects on the proliferation and DNA methylation of cancer cells have not previously been compared in a single study.

In the present study, in vitro cultured human gastric cancer cells (hGCCs) were studied, following treatment with various concentrations of 5-Fu or 5-aza. The effects of these two types of drug on the proliferation and DNA methylation of hGCCs, as well as their underlying mechanisms, were investigated by cell counting, MTT assay and methyl-sensitive amplified polymorphism (MSAP).

\section{Materials and methods}

Reagents. Unless otherwise indicated, all chemicals were purchased from Sigma-Aldrich (St. Louis, MO, USA). 
Cell cultured in vitro. The MGC-803 hGCC line (obtained from Inner Mongolia Medical University, Hohhot, China) was cultured in RPMI-1640 complete medium [RPMI-1640 medium (Gibco Life Technologies, Carlsbad, CA, USA) supplemented with $10 \%(\mathrm{v} / \mathrm{v})$ fetal bovine serum (Gibco Life Technologies), $100 \mathrm{IU} / \mathrm{ml}$ penicillin and $100 \mu \mathrm{g} / \mathrm{ml}$ streptomycin], at $37^{\circ} \mathrm{C}$ in a humidified atmosphere of $5 \% \mathrm{CO}_{2}$. When hGCCs entered the exponential phase, they were removed with digestion medium [D-Hanks medium supplemented with $0.25 \%(\mathrm{~m} / \mathrm{v})$ trypsin and $0.05 \%(\mathrm{~m} / \mathrm{v})$ EDTA], washed 2-3 times in RPMI-1640 complete medium, transplanted into 96-well tissue culture plates at a density of $2 \times 10^{5}$ live cells $/ \mathrm{ml}$ and cultured in RPMI-1640 complete medium supplemented with various concentrations of $5-\mathrm{Fu}$ $(10,20,30$ and $40 \mathrm{~g} / \mathrm{l})$ or 5 -aza $(5,10,15$ and $20 \mu \mathrm{mol} / \mathrm{l})$. hGCCs were cultured in the conditions described above, and used for subsequent experiments. The culture medium was refreshed every $24 \mathrm{~h}$.

Cell counting. Following $24 \mathrm{~h}$ of treatment with 5-Fu or 5-aza, the proliferation of hGCCs was evaluated by cell counting. Briefly, hGCCs were removed by digestion medium, dyed with $0.4 \%(\mathrm{~m} / \mathrm{v})$ trypan blue medium (trypan blue was supplemented into RPMI-1640 complete medium) for $3 \mathrm{~min}$ and mounted on an inverted microscope (Eclipse Ti-U; Nikon Corporation, Tokyo, Japan) for living cell counting. Cell counting was performed every $24 \mathrm{~h}$ from day 1 (following $24 \mathrm{~h}$ of drug treatment) to day 7 . Each treatment, as well as the controls (cultured in RPMI-1640 complete medium alone), was repeated 3 times.

MTT assay. On days 3 and 6, the proliferation inhibition of hGCCs was evaluated by MTT assay. Briefly, MTT solution [MTT dissolved in phosphate-buffered saline (PBS)] was added into each well at a final concentration of $200 \mathrm{mg} / \mathrm{l}$. Subsequently, plates were incubated in identical conditions to those described above for $3 \mathrm{~h}$. Following removal of the supernatant, $150 \mu \mathrm{l}$ dimethyl sulfoxide was added to each well, plates were slightly oscillated for $10 \mathrm{~min}$ and the absorbance $(A)$ of each well at $490 \mathrm{~nm}$ was recorded using a Microplate Reader (Synergy HT; BioTek Instruments, Inc., Winooski, VT, USA). Each treatment, as well as the control, was repeated 4 times.

Extraction of genomic DNA from hGCCs. On day 3, hGCCs were removed by digestion medium and washed 2-3 times in PBS medium prior to genomic DNA extraction using a cell genome DNA extraction kit (TianGen Biochemistry Technology Co., Ltd, Beijing, China) according to the manufacturer's instructions, and stored at $-20^{\circ} \mathrm{C}$ for subsequent experiments.

MSAP assay. Genomic DNA was digested with EcoRI/MspI [Promega (Beijing) Biotech Co., Ltd, Beijing, China] or EcoRI/HapII [Promega (Beijing) Biotech Co., Ltd], respectively. The digestion mixture consisted of $20 \mu \mathrm{l}$ genomic DNA, $2 \mu \mathrm{l}$ EcoRI, $2 \mu \mathrm{l}$ MspI (or HapII), $5 \mu \mathrm{l} 10 \mathrm{X}$ buffer and $21 \mu \mathrm{l}$ double distilled $(\mathrm{dd}) \mathrm{H}_{2} \mathrm{O}$, in a total volume of $50 \mu \mathrm{l}$. Digestion was performed at $37^{\circ} \mathrm{C}$ for $6 \mathrm{~h}$.

Two adaptors were designed as described previously (12). These were HapII/MspI (H-M) adaptor:
H-M(I), 5'-GACGATGTCTAGAA-3' and H-M(II), 5'-CGTTCTAGACTCATC-3'; and EcoRI (E) adaptor: E(I), 5'-CTCGTAGACTGCGTACC-3' and E(II), 5'-AATTGGTACGCAGTCTAC-3'. The connection mixture consisted of $12.5 \mu \mathrm{l}$ digestion product, $5 \mu \mathrm{l}(10 \mathrm{pmol}) \mathrm{H}-\mathrm{M}$ adaptor, $5 \mu \mathrm{l}$ (10 pmol) E adaptor, $3 \mu \mathrm{l}$ T4 DNA ligase, $5 \mu \mathrm{l} 10 \mathrm{X}$ connection

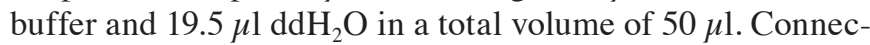
tions were performed at $16^{\circ} \mathrm{C}$ overnight, prior to inactivation of T4 DNA ligase (Takara Biotechnology Co., Ltd., Dalian, China), at $65^{\circ} \mathrm{C}$ for $8 \mathrm{~min}$. Subsequently, the connection product was stored at $-20^{\circ} \mathrm{C}$ for subsequent experiments.

A pair of primers was designed for the pre-polymerase chain reaction (PCR), as described previously (12), which were as follows: Forward, 5'-GATGAGTCTAGAACGGT-3' and reverse, 5'-GACTGCGTACCAATTCA-3'. The pre-PCR reaction mixture consisted of $0.5 \mu 1$ connection product, $1 \mu 1$ forward primer $(30 \mathrm{ng} / \mu \mathrm{l}), 1 \mu \mathrm{l}$ reverse primer $(30 \mathrm{ng} / \mu \mathrm{l})$, $1.6 \mu \mathrm{l}$ dNTPs (2.5 mM each; Takara Biotechnology Co., Ltd.), $1.2 \mu \mathrm{lgCl}_{2}(25 \mathrm{mM}), 1 \mu \mathrm{l}$ raq $(5 \mathrm{U} / \mu \mathrm{l}$; Takara Biotech-

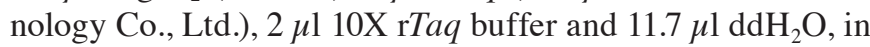
a total volume of $20 \mu \mathrm{l}$. Pre-PCR was performed as follows: Holding at $94^{\circ} \mathrm{C}$ for $5 \mathrm{~min}$, then 30 cycles of denaturation at $94^{\circ} \mathrm{C}$ for $30 \mathrm{sec}$, annealing at $56^{\circ} \mathrm{C}$ for $1 \mathrm{~min}$ and extension at $72^{\circ} \mathrm{C}$ for $1 \mathrm{~min}$, followed by a final extension at $72^{\circ} \mathrm{C}$ for $7 \mathrm{~min}$. The PCR products were loaded onto $0.8 \%$ agarose gel for electrophoresis and stained with ethidium bromide.

The primers used for selective amplification were as follows: Forward, 5'-GATGAGTCTAGAACGGTNN-3' and reverse, 5'-GACTGCGTACCAATTCANN-3', where N was any one of the A, T, C or G nucleotides. In the present study, 5 forward primers (5'-GATGAGTCTAGAACGGTGC-3', 5'-GATGAGTCTAGAACGGTAT-3', 5'-GATGAGTCTAGA ACGGTCA-3', 5'-GATGAGTCTAGAACGGTTC-3' and 5'-GATGAGTCTAGAACGGTAG-3) and 5 reverse primers (5'-GACTGCGTACCAATTCACT-3', 5'-GACTGCGTACCA ATTCAAG-3', 5'-GACTGCGTACCAATTCATA-3', 5'-GAC TGCGTACCAATTCAGT-3' and 5'-GACTGCGTACCA ATTCAAC-3') were randomly matched, so that a total of 25 pairs were used. The selective amplification reaction mixture consisted of $0.2 \mu \mathrm{l}$ pre-PCR products, $1 \mu \mathrm{l}$ forward primer (30 ng/ $\mu \mathrm{l}), 1 \mu \mathrm{l}$ reverse primer (30 ng/ $\mu \mathrm{l}), 1.6 \mu \mathrm{l} \mathrm{dNTPs}$ (2.5 mM each), $1.2 \mu 1 \mathrm{MgCl}_{2}(25 \mathrm{mM}), 0.5 \mu \mathrm{rTaq}(5 \mathrm{U} / \mu \mathrm{l})$,

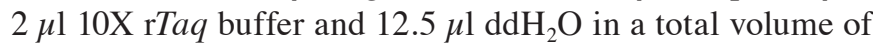
$20 \mu 1$. Selective amplification was performed under the following conditions: Holding at $94^{\circ} \mathrm{C}$ for $5 \mathrm{~min}$, then 13 cycles of denaturation at $94^{\circ} \mathrm{C}$ for $30 \mathrm{sec}$, annealing at $65^{\circ} \mathrm{C}$ (each cycle decreased by $0.7^{\circ} \mathrm{C}$ ) for $30 \mathrm{sec}$ and extension at $72^{\circ} \mathrm{C}$ for $1 \mathrm{~min}$, followed by 23 cycles of denaturation at $94^{\circ} \mathrm{C}$ for $30 \mathrm{sec}$, annealing at $56^{\circ} \mathrm{C}$ for $30 \mathrm{sec}$ and extension at $72^{\circ} \mathrm{C}$ for $1 \mathrm{~min}$, and further extension at $72^{\circ} \mathrm{C}$ for $7 \mathrm{~min}$. The PCR products were loaded onto $10 \%$ polyacrylamide gel for electrophoresis and stained with silver nitrate, then developed with $1.5 \%(\mathrm{w} / \mathrm{v})$ sodium hydroxide and $0.4 \%(\mathrm{v} / \mathrm{v})$ formaldehyde.

Statistical analysis. Differences in the proliferation and proliferation inhibition of hGCCs were statistically compared by one-way and two-way analysis of variance, respectively. Differences in the levels of DNA methylation were statistically compared by $\chi^{2}$ analysis. SPSS software version 19.0 


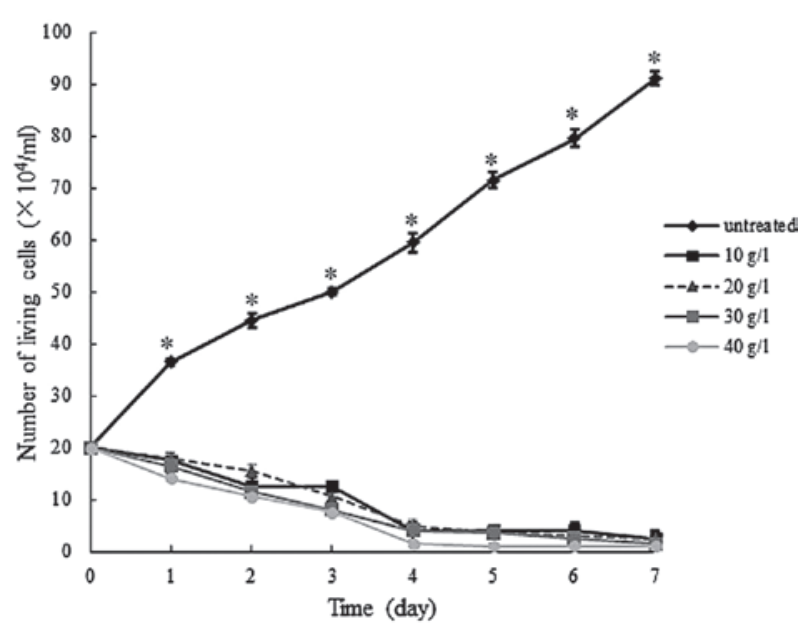

Figure 1. Proliferation of human gastric cancer cells following treatment with various concentrations of $5-\mathrm{Fu}$. Data are presented as the mean \pm standard deviation. ${ }^{*} \mathrm{P}<0.05$ vs. all 5-Fu treated groups. 5-Fu, 5-fluorouracil.

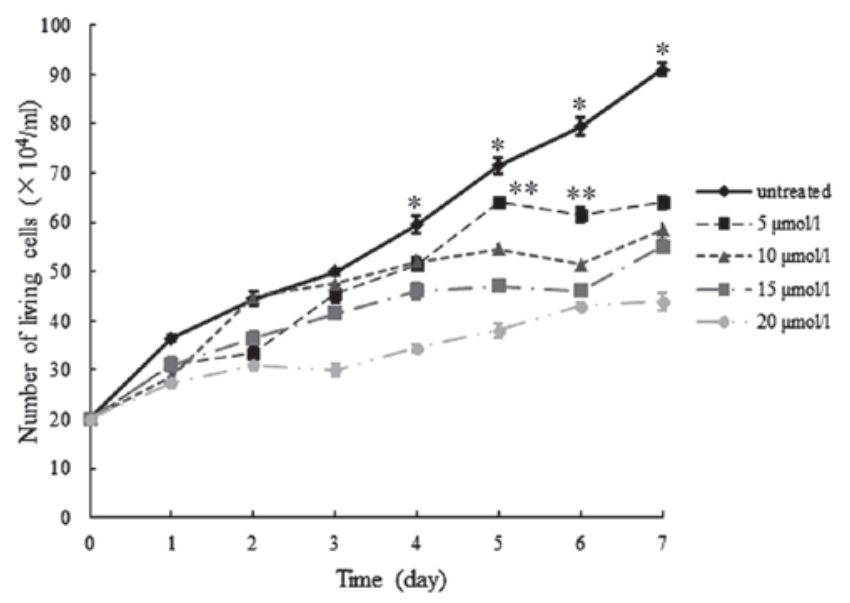

Figure 2. Proliferation of human gastric cancer cells following treatment with various concentrations of 5 -aza. Data are presented as the mean \pm standard deviation. ${ }^{*} \mathrm{P}<0.05$ vs. all 5 -aza treated groups (days $4-7$ ). ${ }^{* *} \mathrm{P}<0.05$ vs. all 5-aza treated groups (days 5 and 6). 5-aza, 5-azacitidine.

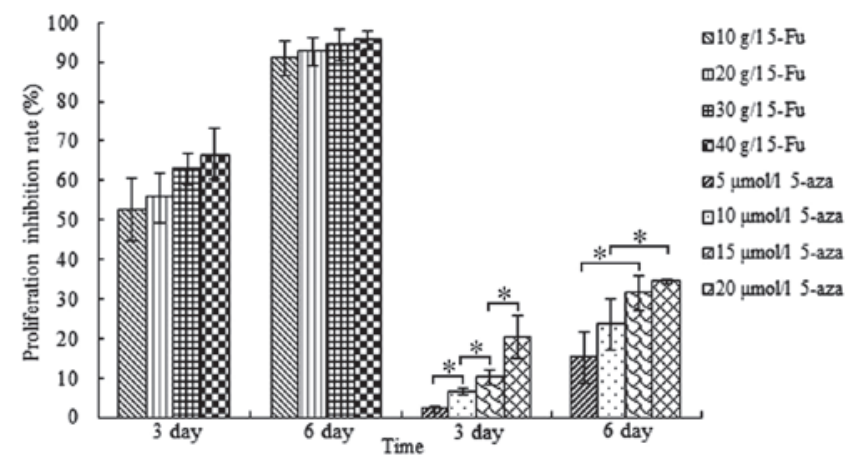

Figure 3. Proliferation of hGCCs is inhibited following treatment with 5-aza. Proliferation rate of hGCCs following treatment with various concentrations of 5-Fu or 5-aza. Data are presented as the mean \pm standard deviation. ${ }^{*} \mathrm{P}<0.05$. 5-Fu, fluorouracil; 5-aza, 5-azacitidine; human gastric cancer cells.

(IBM SPSS, Armonk, NY, USA) was used for statistical analyses, and $\mathrm{P}<0.05$ was considered to indicate a statistically significant difference.

\section{Results}

hGCC proliferation is downregulated following treatment with 5-Fu or 5-aza. Following treatment with various concentrations of 5-Fu or 5-aza, the proliferation of hGCCs was evaluated by living cell counting, and the results are presented in Figs. 1 and 2.

As indicated in Fig. 1, following treatment with various concentrations of 5-Fu, the hGCCs began to die from day 1 to 7 , whereas untreated hGCCs were able to proliferate continuously during this period. The difference in the number of living cells between the untreated and 5-Fu-treated groups was significant $(\mathrm{P}<0.05)$ from day 1 to 7 ; however, this difference was not significant $(\mathrm{P}>0.05)$ among the 5 -Fu-treated groups.

In addition, following treatment with various concentrations of 5-aza, hGCCs remained able to proliferate; however, compared with that of the untreated group, the proliferation rate of the 5-aza-treated groups was markedly slower, and the difference in the number of living cells between the untreated and 5-aza-treated groups was significant on days 4-7 $(\mathrm{P}<0.05)$. Furthermore, significant differences among each 5-aza-treated group appeared on day 5 and lasted to day $7(\mathrm{P}<0.05)$. However, on day 7 , the difference between the 10 and $15 \mu \mathrm{mol} / 1$ group was not significant ( $\mathrm{P}>0.05$; Fig. 2).

Proliferation of hGCCs is inhibited following treatment with 5-Fu or 5-aza. Following 3 and 6 days of treatment with various concentrations of 5 -Fu or 5-aza, the inhibition of hGCC proliferation was measured by MTT assay and calculated using the following formula: Cell proliferation inhibition rate $(\%)=[1-A 490($ experimental group $) / A 490$ (control group) $]$ $\mathrm{x} 100$, as described previously (11).

As shown in Fig. 3, 5-Fu effectively inhibited the proliferation of hGCCs, and the inhibition rate was time-dependent, but not concentration-dependent from 10 to $40 \mathrm{~g} / \mathrm{l}$, as no significant differences in inhibition rate were observed among the various treatment groups. The proliferation of hGCCs was also inhibited by 5 -aza treatment, and the inhibition rate was time- and concentration-dependent. However, compared with 5-Fu, the inhibitory effect of 5-aza on the proliferation of hGCCs was weaker. These results were in accordance with the results of the living cell counting assay.

Treatment with 5-aza decreases DNA methylation levels in $h G C C s$. Following 3 days of treatment with various concentrations of 5-Fu or 5-aza, the levels of DNA methylation were measured by MSAP assay.

As shown in Fig. 4, the products of selective amplification were run on polyacrylamide gel, and each sample of hGCCs genomic DNA displayed an $\mathrm{H}$ lane and an $\mathrm{M}$ lane, which corresponded to the products of EcoRI/HapII and EcoRI/MspI digestion, respectively. The number of bands in the pairs of lanes indicated the quantity of products of genomic DNA samples amplified by each pair of primers. The bands could be divided into three types. If the band was detected in the $\mathrm{H}$ and M lane, this band represented a non-methylated site (I; Fig. 4); if the band presented only in the $\mathrm{H}$ lane, this band represented a hemimethylated site (II; Fig. 4); and if the band presented only in the $\mathrm{M}$ lane this band represented a methylated site 
Table I. Levels of DNA methylation of human gastric cancer cells following treatment with various concentrations of fluorouracil or 5-azacitidine.

A, DNA methylation following fluorouracil treatment

\begin{tabular}{lccc}
\hline Concentration, g/l & $\begin{array}{c}\text { No. methylated sites, } \mathrm{n} \\
\text { (methylation level, \%) }\end{array}$ & $\begin{array}{c}\text { No. hemimethylated sites, } \mathrm{n} \\
\text { (hemimethylation level, \%) }\end{array}$ & No. non-methylated sites \\
\hline Control & $92(22.2)$ & $30(7.2)$ & 292 \\
10 & $96(21.6)$ & $42(9.4)$ & 306 \\
20 & $87(20.9)$ & $38(9.1)$ & 292 \\
30 & $77(20.6)$ & $36(9.7)$ & 260 \\
40 & $70(19.9)$ & $40(11.4)$ & 241 \\
\hline
\end{tabular}

B, DNA methylation following 5-azacitidine treatment

\begin{tabular}{lccc}
\hline Concentration, $\mu$ mol/1 & $\begin{array}{c}\text { No. methylated sites, } \mathrm{n} \\
\text { (methylation level, \%) }\end{array}$ & $\begin{array}{c}\text { No. hemimethylated sites, } \mathrm{n} \\
\text { (hemimethylation level, \%) }\end{array}$ & No. non-methylated sites \\
\hline Control & $92(22.2)$ & $30(7.2)$ & 292 \\
5 & $91(18.1)^{\mathrm{a}}$ & $16(3.2)^{\mathrm{a}}$ & 396 \\
10 & $85(17.7)^{\mathrm{a}}$ & $12(2.5)^{\mathrm{a}}$ & 384 \\
15 & $77(17.1)^{\mathrm{a}}$ & $10(2.2)^{\mathrm{a}}$ & 362 \\
20 & $60(15.3)^{\mathrm{a}}$ & $6(1.5)^{\mathrm{a}}$ & 325 \\
\hline
\end{tabular}

${ }^{\mathrm{a}} \mathrm{P}<0.05$ vs. control.

(III; Fig. 4). The number of bands amplified by all the pairs of primers was counted, and the levels of methylation, hemimethylation and total methylation were calculated according to the following formulae:

Level of hemimethylation $=$ (number of hemimethylated bands)/(total number of bands)

Level of methylation $=($ number of methylated bands $) /($ total number of bands).

As indicated in Table I, following 3 days of treatment with various concentrations of 5-Fu, the levels of methylation and hemimethylation in hGCC genomic DNA were not significantly altered $(\mathrm{P}>0.05)$. This result indicated that 5-Fu was unable to markedly alter the level of DNA methylation in the hGCC genome. However, following 3 days of treatment with various concentrations of 5-aza, the levels of DNA methylation and hemimethylation in the hGCC genome were significantly decreased $(\mathrm{P}<0.05)$, compared with those of the untreated group, and the differences were not significant amongst each of the 5-aza treatment groups $(\mathrm{P}>0.05)$.

\section{Discussion}

In the present study, the effects of two nucleoside antitumor drugs, 5-Fu and 5-aza, on the proliferation of hGCCs were investigated. The results of living cell counting and MTT assay revealed that 5-Fu more efficiently inhibited the proliferation of hGCCs than 5-aza. This may be due to differences in the anticancer mechanism of these two types of drug. 5-Fu is an antimetabolite drug, which may be intracellularly converted into several active metabolites. These metabolites are able to form a stable ternary complex with thymidylate synthase

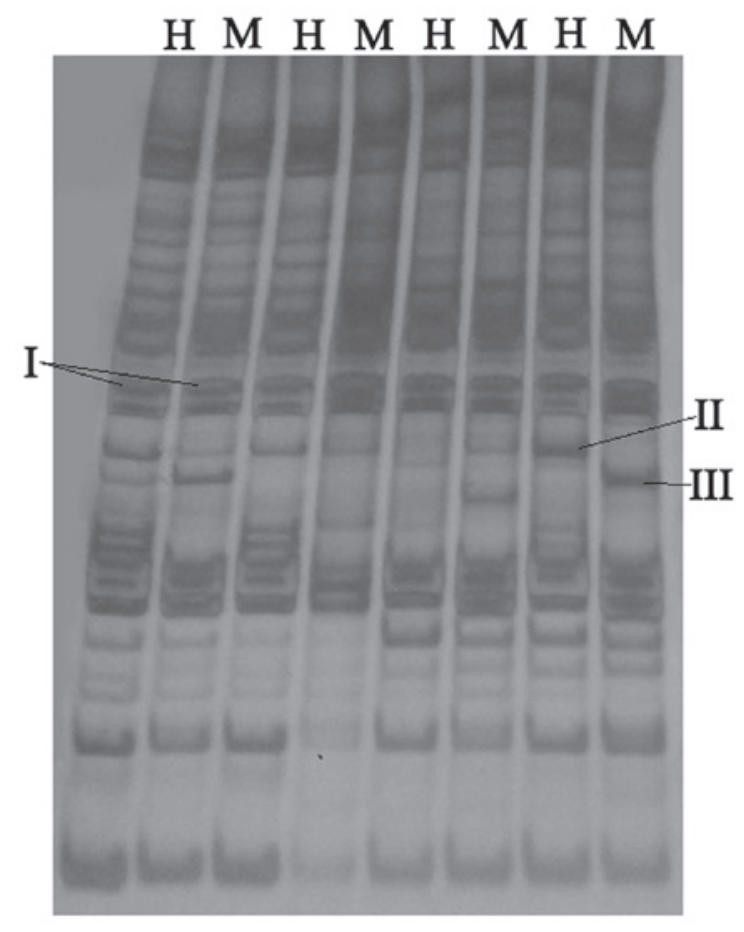

Figure 4. Results of methyl sensitive amplified polymorphism assay. Lanes: $\mathrm{H}$, products of $E c o \mathrm{RI} / H a p \mathrm{II}$ digestion; M, products of $E c o \mathrm{RI} / M s p \mathrm{I}$ digestion. I, II and III indicate non-methylated, hemimethylated and methylated sites, respectively.

and 5,10-methylenetetrahydrofolate, or misincorporate into DNA and RNA, disrupting DNA synthesis and repair or RNA processing and function (9). Therefore, 5-Fu exerts lethal effects 
on cancer cells only in a single cell cycle. By contrast, 5-aza is a type of DNA methyltransferase inhibitor, which is able to induce degradation of DNA methyltransferase 1 (DNMT1), resulting in DNA demethylation and the re-expression of certain silenced tumor suppressor genes, as well as inhibiting the proliferation of cancer cells $(11,13)$. Therefore, 5 -aza is able to inhibit the uncontrolled proliferation of cancer cells through multiple cell cycles, which explains why the inhibitory effect of 5-aza on the proliferation of hGCCs was weaker than that of 5-Fu in the present study.

Previous studies have indicated that following treatment of cancer cells with 5-aza, certain tumor suppressor genes, including p16, DAPK, MGMT, FHIT, CDKN2B, ESR1 and $I G S F 4$, exhibited DNA demethylation and were subsequently re-expressed $(11,13)$; however, changes in the levels of DNA methylation at the genome scale were not examined in these studies. In the present study, an MSAP assay was performed to examine the levels of DNA methylation in the hGCC genome. The results revealed that 5 -aza was able to significantly decrease the levels of DNA methylation and hemimethylation in the hGCC genome, whereas 5-Fu was not. This result was consistent with the differences in the anticancer mechanism of these two types of drugs, and indicated that 5-aza was able to decrease the activity of DNMT1, a type of maintenance methyltransferase, which methylates hemimethylated DNA strands following S phase. MSAP technology may be used to test the genome-wide levels of DNA methylation, particularly when sequence information for the genome is unavailable. This technology is reliable, inexpensive and relatively simple, therefore MSAP has been widely used to analyze DNA methylation changes in plants and animals (14-16). Recently, MSAP technology was used to successfully examine the level of DNA methylation of sheep cloned embryos at various development stages (12).

In conclusion, the two types of nucleoside antitumor drug, 5-Fu and 5-aza, inhibited the proliferation of hGCCs; however, 5-Fu was more efficient than 5-aza. In addition, 5-aza was able to decrease the levels of DNA methylation in the hGCC genome, whereas 5-Fu was not. These results reflect the distinct effects and mechanisms of these two types of drug on the proliferation of hGCCs. Although epigenetic therapy was previously highly recommended to treat cancer, the results of the present study indicate that the slow effect of this type of treatment should be taken into consideration. Instead, it is proposed that a combination of metabolic and epigenetic treatment may be a more favorable therapeutic strategy.

\section{Acknowledgements}

The present study was supported by the National Natural Science Foundation of China (no. 31160245), the Program for Young Talents of Science and Technology in Universities of Inner Mongolia Autonomous Region, the Natural Science Foundation of Inner Mongolia Autonomous Region of China (no. 2012MS0503) and the Innovation Foundation of Inner Mongolia University of Science \& Technology (no. 2011NCL007).

\section{References}

1. Taby R and Issa JP: Cancer epigenetics. CA Cancer J Clin 60: 376-392, 2010.

2. Vogelstein B and Kinzler KW: Cancer genes and the pathways they control. Nat Med 10: 789-799, 2004.

3. McCabe MT, Brandes JC and Vertino PM: Cancer DNA methylation: Molecular mechanisms and clinical implications. Clin Cancer Res 15: 3927-3937, 2009.

4. Antelo M, Balaguer F, Shia J, Shen Y, Hur K, Moreira L, Cuatrecasas M, Bujanda L, Giraldez MD, Takahashi M, et al: A high degree of LINE-1 hypomethylation is a unique feature of early-onset colorectal cancer. PLoS One 7: e45357, 2012.

5. Rauch TA, Zhong X, Wu X, Wang M, Kernstine KH, Wang Z, Riggs AD and Pfeifer GP: High-resolution mapping of DNA hypermethylation and hypomethylation in lung cancer. Proc Natl Acad Sci USA 105: 252-257, 2008.

6. Howard G, Eiges R, Gaudet F, Jaenisch R and Eden A: Activation and transposition of endogenous retroviral elements in hypomethylation induced tumors in mice. Oncogene 27: 404-408, 2008.

7. Osborne C, Wilson P and Tripathy D: Oncogenes and tumor suppressor genes in breast cancer: Potential diagnostic and therapeutic applications. Oncologist 9: 361-377, 2004.

8. Stresemann C, Brueckner B, Musch T, Stopper H and Lyko F: Functional diversity of DNA methyltransferase inhibitors in human cancer cell lines. Cancer Res 66: 2794-2800, 2006.

9. Longley DB, Harkin DP and Johnston PG: 5-fluorouracil: Mechanisms of action and clinical strategies. Nat Rev Cancer 3: 330-338, 2003.

10. Christman JK: 5-Azacytidine and 5-aza-2'-deoxycytidine as inhibitors of DNA methylation: Mechanistic studies and their implications for cancer therapy. Oncogene 21: 5483-5495, 2002.

11. Su Y, Xu H, Xu Y, Yu J, Xian Y and Luo Q: Azacytidine inhibits the proliferation of human promyelocytic leukemia cells (HL60) by demethylation of MGMT, DAPK and p16 genes. Hematology 17: 41-46, 2012.

12. Ma LB and He XY: The levels of DNA methylation of sheep cloned embryos in different development stages. Indian J Anim Res 48: 221-226, 2014.

13. Tran HT, Kim HN, Lee IK, Kim YK, Ahn JS, Yang DH, Lee JJ and Kim HJ: DNA methylation changes following 5-azacitidine treatment in patients with myelodysplastic syndrome. J Korean Med Sci 26: 207-213, 2011.

14. Paun O, Bateman RM, Fay MF, Hedrén M, Civeyrel L and Chase MW: Stable epigenetic effects impact adaptation in allopolyploid orchids (Dactylorhiza: Orchidaceae). Mol Biol Evol 27: 2465-2473, 2010.

15. Xu Y, Zhao Q, Mei S and Wang J: Genomic and transcriptomic alterations following hybridisation and genome doubling in trigenomic allohexaploid Brassica carinata x Brassica rapa. Plant Biol (Stuttg) 14: 734-744, 2012.

16. Yang C, Zhang M, Niu W, Yang R, Zhang Y, Qiu Z, Sun B and Zhao Z: Analysis of DNA methylation in various swine tissues. PLoS One 6: e16229, 2011. 